\title{
Students' First Language Skills After Six Years in Bilingual Education
}

\author{
Tuula Merisuo-Storm \\ Marjaana Soininen \\ University of Turku, Finland, Department of Education, Rauma Unit \\ tuumer@utu.fi \\ marjasoi@utu.fi
}

DOI:10.5901/mjss.2014.v5n22p72

\begin{abstract}
The longitudinal study investigated the effects of Content and Language Integrated Learning (CLIL) on the development of children's literacy skills during their first six school years. In the three CLIL classes students studied, from the very beginning of the first grade, different school subjects in Finnish and in English. Three other classes were used as a control group. The students in those classes studied all school subjects in Finnish and started to learn English as a second language in third grade. At the beginning of the first grade, the level of school readiness was significantly higher in the bilingual classes than in the monolingual classes. At the end of the first grade, there was no significant difference in the literacy skills of the two groups, but after two study years, the reading and writing skills of the test group were significantly better than those of the control group. After four school years it was obvious that the children's creative writing skills had also benefited from bilingual teaching. The students in the CLIL classes had learned to pay attention to languages, as well to their mother tongue as to other languages. Moreover, they had more positive attitudes towards reading, writing and foreign language learning. Especially the boys' attitudes proved to be more positive in the CLIL classes than in the other classes. In addition, they enjoyed studying English and also studying through it. The students' spelling skills and ability to understand different texts were measured during the last month of their sixth school year. The measurements showed that the students in the CLIL classes had achieved significantly better first language spelling and reading skills than the students in the other classes. They made significantly less spelling errors and understood significantly better fiction, non-fiction, and newspaper texts. Furthermore, they showed more proficiency in deriving the meaning of new words from the written context than the other students. They succeeded significantly better in finding the most important facts of the non-fiction text and summarising the text than their peers in the other classes. It is worth mentioning that especially the boys seemed to have benefited from bilingual education: in the other classes the girls' skills were significantly better than the boys' but this was not the case in the CLIL classes.
\end{abstract}

Keywords: Content and Language Integrated Learning (CLIL), primary education, literacy skills, learning attitudes

\section{Introduction}

Foreign language competence is one of the main determinants of learning as well as personal mobility. Foreign language skills are needed for studying, employment, understanding of own and other cultures, and personal fulfilment. (Commission of the European Communities 2007.) However, a European survey on students' language competences shows that at the end of lower secondary education only four in ten students are able to have a simple conversation in a foreign language. At the same time, almost half of the Europeans say that taking part in a conversation in any foreign language is impossible for them. Consequently, it is important to improve the quality and increase the quantity of language teaching. This requires efforts in terms of teacher training, the development of new materials, and teaching methods. These investments will have a significant return, improving the efficiency of the whole labour market. The goal is that by 2020 , at least $50 \%$ of 15 year olds is able to have a simple conversation in their first foreign language and at least $75 \%$ of the students in lower secondary education is studying at least two foreign languages. (Commission of the European Communities 2012.)

The national education systems of each state should enhance their efficiency in giving their students the language competences they need. The focus should be in 1) quantity (through early start, increased provision, teaching at least two foreign languages to all students, and increased exposure at school and through the media); 2) quality (through innovative teaching methods and teacher training, better opportunities of using language skills, Content and Language Integrated Learning (CLIL), and development of ICT-based language learning resources); and 3) monitoring of learning results in order to identify strengths and weaknesses. Content and Language Integrated Learning (CLIL), mentioned above, can be an 
exceptionally efficient learning method because it increases language exposure, improves motivation, and links language acquisition to themes that have a concrete relevance for the learners. (Commission of the European Communities 2012.)

However, many educators and parents are concerned that teaching through a foreign language may have negative effects on the development of children's first language skills. In teaching, one should take into account that a child's mother tongue is the basis of all learning. A considerable amount of work in school involves reading and activities closely related to reading. Reading skills, including being capable of discovering the meaning and of finding information in written texts, and learning to remember this information and to relate it to previous knowledge, are the necessary tools for the study of almost any subject of instruction. (Hannon 1997; Whitehead 1999.) A child who does not learn to read and comprehend different texts in the early school years will have severe difficulties also when studying other school subjects. For instance, when studying mathematics and practical school subjects a student has to read and understand various instructions in order to carry out a task or solve a problem. Good readers are more successful in almost any school subjects than those whose reading skills are poor. Therefore, it is important to develop the children's language-based study skills systematically. They should acquire knowledge of language and literature in increasingly demanding language-usage situations and learn to evaluate and observe themselves as readers. Furthermore, they should learn strategies that help them to comprehend these diverse texts. The older the students get the more they need good reading skills to acquire new information and the more complex texts they have to be able to comprehend. (Bowyer-Grane \& Snowling, 2005; National Core Curriculum for Basic Education, 2004; McGee \& Johnson, 2003.)

In CLIL, the content of all teaching has to be concise in order to leave sufficiently time for teaching through a foreign language. The risk that this involves is that the children may not have enough time to practise their literacy skills. In today's society it is important that children achieve a good, versatile command of both their first language and foreign languages. Therefore, it was a matter of importance to find out whether CLIL can affect the development of children's literacy skills in a negative manner. Another matter that has caused concern amongst educators is the literacy skills of boys. In PISA 2012 (the OECD Programme for International Student Assessment) girls achieved better scores than boys in reading literacy in all OECD countries. A disquieting result is that between PISA 2000 and PISA 2012 the gender gap in reading performance widened in 11 countries. To close the gender gap in reading performance, new ideas aiming to attract interest and engagement among boys in literary culture are badly needed. (OECD, 2013; Välijärvi et al., 2007.) The aim of the study described in this article was to find out whether students' reading and writing skills develop equally well in CLIL as in regular education. Moreover, the study aimed to explore if there was a difference in the development of boys' and girls' literacy skills in CLIL and in regular classes.

\section{First language skills}

Reading is thinking cued by written language. A skilful reader finds - when reading fiction as well as non-fiction - several pieces of information in the text that make the understanding easier. Effective readers locate the basic facts from the text. When reading non-fiction, a reader needs to comprehend the topic, learn new facts related to it, and be able to find and remember the important information. (Scharer, Pinnell, Lyons, \& Fountas, 2005.)

There are four key elements that are central to comprehension processes: prior knowledge, inferential reasoning, selfregulation, and affective variables connected to efficacy and motivation. The readers with prior knowledge of the topic and the structure of an informational text are the most able to mentally organize and remember the ideas the text provides. Inferential reasoning refers to a reader's ability to 'read between lines'. He or she makes connections that are not clearly expressed in the text. Inferential reasoning is an essential factor of skilled reading. A reader with sufficient prior knowledge of the topic makes more inferences than a less knowledgeable reader in order to make his or her comprehension easier. The term self-regulated reading refers to self-questioning and repair processes. Skilful readers are consciously aware of efficient information-seeking processes. They control these processes by choosing alternative strategies when others do not work. (Coiro \& Dobler, 2007.)

Good readers summarise while reading and it helps them to remember and connect the important ideas of the text. Nevertheless, many students struggle with determining the main ideas and themes of the text as well as combining similar ideas, and synthesising them into a coherent whole. Often they just repeat most of the text or give a very vague statement. Still, a good summary should give a whole picture of the story and include only the important parts in the same order as the text as well as knowledge of how they are related. (Diehl, 2005.)

The process of writing can be defined as planning and reviewing. Planning includes idea generating, translating involves text generating and transcription, and reviewing comprises evaluating and revising. To become a good writer a student 
needs to learn to construct meaningful sentences that express his or her ideas, emotions and views appropriately and in a creative and mature style. In addition, a writer should have knowledge of how to use grammatically accurate language and adequate syntactic, morphological and semantic elements in his or her texts. (Berninger, Abbot, Whitaker, Sylvester, \& Nolen, 1995; Hurry \& Doctor, 2007.)

An important goal of literacy teaching is to awaken students' interest in language and literature and give them a lasting positive attitude towards reading. Children who are motivated to read spend more time reading than their less motivated peers. Unfortunately, poor readers are often unmotivated to read. Consequently, the difference between their respective levels of reading skills becomes even more significant. The aim of literacy teaching is to support the development of students' ability to read, interpret and use different texts. Each student should adopt a habit of evaluating and observing himself or herself as a reader. In addition, he or she should learn to select appropriate reading material for different purposes and to find information in various sources. (Merisuo-Storm, 2006.)

There are numerous reasons why a person can be interested in reading and writing. Children can read for pleasure, to get new information, or because it is a part of a classroom task. Writing can be a tool for social interaction or a creative activity a child enjoys. Consequently, one can consider reading and writing as tools to be used in learning and communicating but also as interesting activities. (Nolen, 2007.)

\section{Content and language integrated learning (CLIL)}

There are at least thirty-three different terms that refer to some type of bilingual education. For instance, 'content-based language teaching', 'language-based content instruction', 'language sensitive content instruction', and 'content-enhanced teaching' refer to bilingual models where language and content are integrated. The term 'immersion' should only be used to refer to Canadian bilingual education and its replicas elsewhere. In European Union, two acronyms are used to distinguish European bilingual education models from other similar programs elsewhere: CLIL for Content and Language Integrated Learning and EMILE for Enseignement d'une matiére intégrée á une langue étrangére. CLIL is an umbrella term that is used to describe educational methods where subjects are taught through a foreign language. It refers to an educational approach where curricular content is taught through the medium of a foreign language to students participating in some form of mainstream education at the primary, secondary, or tertiary level. However, it does not cover language maintenance programs for minority or lesser-used languages. In those programs, the entire curriculum is given in the minority language for its speakers. For instance, in Wales there are schools where Welsh-speaking children are taught in Welsh. In addition, teaching children of immigrant language backgrounds in mainstream language is not considered CLIL education either. (Beardsmore, 2009; Dalton-Puffer, 2011.)

The acronym CLIL is the platform for a methodological approach of far broader scope than language teaching. It aims to develop proficiency in a curriculum subject as well as in the language through which it is taught. Achieving this twofold goal requires an integrated approach to instruction and learning. In CLIL education, the non-language subject is not taught in a foreign language but with and through a foreign language. Therefore, the teachers should not only consider how languages should be taught, but also think about the educational process in general. (Beardsmore, 2009; Content and Language Integrated Learning at School in Europe [CLIL], 2005.)

Bilingual education uses two languages to educate generally, purposefully, equitably, and for the tolerance and appraisal of diversity. The narrower goal of foreign language teaching is to learn an additional language. Bilingual education aims also to help students to become global and responsible citizens as they learn to function across cultures and worlds. (García, 2009.) The differences between bilingual education programs and language education programs are displayed in Table 1.

CLIL programs include typically following characteristics: The language used is not a second language (L2) but a foreign language (most often English) that children encounter mainly in the classroom. The teacher is normally not a native speaker of the target language and instead of being a language specialist he or she is most often a content expert. The lessons are timetabled as content lessons (e.g. biology, music, history) and language experts teach the target language separately from CLIL lessons in foreign language lessons. Usually less than half of the contents in the curriculum is taught in the target language. In short, CLIL is a foreign language enrichment attached to content teaching. (Dalton-Puffer 2011; Nikula, DaltonPuffer \& Llinares, 2013.)

The view of content-based language learning as an efficient method of obtaining language proficiency has been supported by Krashen's studies about language learning. He distinguishes between language learning and language acquisition. 
Language acquisition occurs when a person receives and understands messages in a foreign language. It is possible only when he or she has the opportunity to hear a sufficient amount of language. The language material has to be selected to meet, for the most part, the student's level of understanding and yet to be partly beyond it. Thus, it is possible that the student infers the meaning of new words and expressions from the context, and acquires knowledge of the language in the same manner as an infant acquires his or her first language. (Krashen, 1992.)

However, language usage is always interactive and, consequently, it is important that the students are not reduced to passive receivers. They should be encouraged to use the foreign language to communicate meaning and receive feedback from the teacher and from the other students. (Hedge, 2000.) When students get new information through the medium of a foreign language and have opportunities to practise their language skills in genuine communicative situations they find language learning purposeful and learn effectively. (Met, 2004; Richards \& Rodgers, 2001.)

\section{Study}

The main goal of the study was to find out if bilingual education affects the development of students' first language literacy skills negatively or if children in CLIL education achieve the same level of literacy as their peers who study exclusively in Finnish. Another goal was to explore if there is a difference in the development of boys' and girls' literacy skills in CLIL and in regular classes. The development of the students of six classes in three schools in southern Finland was observed from the beginning of the first grade to the end of sixth grade. At the beginning of the first school year in these classes there were 138 students, 78 of them studied in the CLIL classes and 58 in the other classes. In the CLIL classes 20-25 per cent of the teaching was in English.

Table 2 shows what skills were tested in the five measurements that were conducted during the research period. The students' starting level was measured at the very beginning of their first school year. At that time, they were six or seven years old. The initial test was used to measure their general level of school readiness, auditory and visual perception, mathematic skills and memory. The results showed that the students in the CLIL classes had, as a group, better initial skills than the students in the other classes. This was due to the entrance procedures for the CLIL classes. When selecting students, the emphasis in many schools was laid on the applicants' linguistic skills. Therefore, it is not surprising that in the initial test the students in the CLIL classes had considerably more success in the tasks that measured phonological and phonemic awareness. However, it should also be pointed out that although the students in the CLIL classes showed, as a group, a higher starting level, there were on the one hand in the control group students who showed excellent performance in the initial test and on the other hand in the CLIL classes students who had poor initial skills.

The students' spelling skills were measured in first, second, and sixth grade with writing from dictation tests. When the children were in fourth grade the focus was on their creative writing skills and attitudes towards reading, writing and language learning. Three reading tests were used to measure the students' reading skills at the end of the first, the second, and the sixth school year. In the first and the second grade the reading tests included reading aloud and reading comprehension tasks and in sixth grade the reading test measured the students' ability to comprehend different kinds of texts. All the measurements were performed in class, and on average no more than one lesson (45 minutes) was used during the same day for measurements. The test results were analysed using an SPPS program. The results may have been somewhat effected by the loss in the number of the students. At the end of the sixth school year only 60 per cent of the students $(n=134)$ were the same as in the beginning of the first school year. However, it is worth mentioning that in the CLIL classes the wastage rate of the students was notably smaller than in the other classes. The families were in most cases so happy to have their children in a CLIL class that they did not want to move them to another school.

In this article the main focus is on the sixth grade measurements and the results of the previous measurements are presented only briefly.

\section{Writing}

As was mentioned above, the students' spelling skills were measured in first, second, and sixth grade with writing from dictation tests. At the end of the first school year, there was no significant difference in children's spelling skills in the bilingual classes and the other classes. However, after the second study year the students in the CLIL classes made significantly less spelling errors than the students in the other classes $(t=4.83, p=.000)$. At fourth grade, the focus of the study was on the students' creative writing. They wrote a story about someone's journey to a place that is very different from where he or she lived. The writers were encouraged to use colourful and rich language, and invent interesting and 
amusing events. The stories composed by the students in the CLIL classes showed that they had learned to pay attention to their first language as well as to other languages. The Finnish language that they used in their stories was significantly more often colourful and rich than the language in the stories composed in the other classes $(t=5.19, p=.000)$. Furthermore, they described significantly more often and in a more detailed manner the differences between home and the new place $(t=-5.17, p=.000)$, as well as the appearance and the characteristics of the characters $(t=-3.15, p=.002)$. There were 138 stories altogether. When selecting the twenty best stories out of them, the main criteria that were used were their individuality, eventfulness, story structure, rich and colourful language, and fluency of narration. The attention was also paid to the fashion in which the author sketched the difference between home and the new place and described the characters of the story, and whether he or she had shown original thinking or made clever remarks. Of the twenty stories that best met these criteria, seventeen came from the CLIL classes and only three from the other classes.

At the end of the sixth school year the students in the CLIL classes had significantly better spelling skills than their peers in the other classes $(t=4.22, p=.000)$. There was a strong correlation between the results of the sixth grade spelling test and the spelling tests of first and second grade $(r=.44, p=.000 ; r=.65, p=.000)$. Table 3 shows the results of the sixth grade spelling test. In the CLIL classes 23 per cent of the students and only 10 per cent of the students in the other classes had excellent marks. In the other classes 10 per cent of the students had made so many errors in the writing from dictation task that their marks were very poor. No one in the CLIL classes had performed equally poorly in the task. In the regular classes, the girls' marks were significantly better than the boys' marks $(t=-2.76, p=.007)$, however, this was not the case in the CLIL classes. Moreover, the boys' marks in the CLIL classes were significantly better than the boys' marks in the other classes ( $t=4.24, p=.000)$ but there was no significant difference in the marks of the girls of the two groups.

In the sixth grade the most common errors in the students' papers were compound word mistakes and capital letter mistakes. In Finnish language there is a large number of very long words and compound words that are written as one word and often children have difficulties in writing them correctly. It seems, however, that the different ways of writing compound words and using capital letters in Finnish and English had not increased the number of these errors in the CLIL classes. On the contrary, the students in the regular classes made them significantly more often than the students in the CLIL classes $(t=-3.37, p=.001 ; t=-4.46, p=.000)$.

\section{Reading}

After the first and the second school year the students in the CLIL classes read with greater accuracy and speed than the students in the other classes. After two school years, especially the reading comprehension skills were significantly better in the CLIL classes than in the other classes $(t=7.10, p=.000)$. When observing the students who started school with a poor level of school readiness or the students who started school with an excellent level of school readiness, there was no significant difference in regard to the development of literacy skills in the CLIL and the regular classes.

During the last weeks of the sixth school year, the students' reading comprehension skills were measured with a test that consisted of three different texts. In addition, the focus was on the students' ability to derive the meaning of a word from the written context and to summarise a text. The first text was a story written by H.C. Andersen, the second a newspaper article about H.C. Andersen, and the third a non-fiction text about orang-utans and their living conditions in today's world.

H.C. Andersen's story was called "What the old man does is always right". After reading the story, the students answered 20 questions. In this section of the test, the difference between the two groups was not significant $(t=2.21, p=.029$, Table 4). However, the students in the CLIL classes proved to have heard or read more Andersen's stories than their peers in the other classes. They could significantly more often produce a title of another story by Andersen. The difference between the two groups was significant $(\mathrm{t}=4.11, \mathrm{p}=.000)$.

The second text in the reading comprehension test was a newspaper article about H.C. Andersen. After reading the article, the students' task was to answer ten questions and explain the meaning of ten words picked from the text. In these tasks, the students in the CLIL classes performed significantly better than the students in the other classes $(t=3.16, p=.002$, Table 5). Their scores varied from 20 to 8 and the scores of the students in the other classes from 19 to 3 . The students in CLIL classes performed especially better in word explaining task than the students in regular classes. Both, the boys and the girls in CLIL classes had significantly better scores in the task than the boys and the girls in the other classes ( $t=2.65$, $p=.010 ; t=3.25, p=.002$ ).

The third section of the test proved to be the most difficult. The students were asked to read a non-fiction text about orangutans and their living conditions in today's world and then write a five-sentence summary of it. It was stressed that the 
summary should include the most essential aspects of the text. In the CLIL classes there was no difference in the results of the three sections of the test. However, in the other classes finding the most important facts in the text and summing them up into five sentences appeared to be significantly more difficult than answering the questions in the two previous sections. In the CLIL classes almost half of the students (48\%) and in the other classes only 11 per cent of the students achieved excellent or very good marks in this section. In contrast, in the monolingual classes almost half of the students' marks (46\%) were poor or fair but only 13 per cent of the students in the bilingual classes succeeded as poorly in summarising the text. The difference between the marks of the two groups was significant $(t=5.80, p=.000$, Table 6$)$. Also in this section of the test, both the boys and the girls in CLIL classes had significantly better scores than the boys and the girls in the other classes $(t=3.54, p=.001 ; t=4.90, p=.000)$.

\section{Attitudes towards reading, writing and language learning}

The students' attitudes towards reading, writing and language learning were measured at the fourth grade. As was mentioned above, international assessments have shown that there is a significant gender gap in boys' and girls' reading performance in almost all countries. The differences in girls' and boys' skills are mainly due to their different attitudes towards reading related activities. These are a result of gender differences in values, goals and out-of-school activities. To decrease the gender gap, new ideas that seek to attract interest and engagement among boys in literary culture and that help them to find pleasure in reading, are badly needed. (Välijärvi et al., 2007.) Therefore, the positive results of the attitude measurements in CLIL classes were most encouraging.

The instrument that was used was a questionnaire including three twelve item sections (reading, writing, and language learning). Responses were made on a 4-point scale to avoid the possibility that students would select a neutral alternative. At that time the students in the regular classes had been taught English for nearly two years using a formal languageteaching method. There was no significant difference in the attitudes towards reading and writing in the CLIL and the regular classes, whereas the girls' and the boys' opinions differed greatly especially in the regular classes. There the boys' attitudes towards reading and writing were more negative than the girls' attitudes. In the CLIL classes the boys' and the girls' opinions did not differ significantly in any of the twelve items in the reading section of the test. In contrast, in the other classes the boys' and the girls' attitudes towards, for example, reading books and reading aloud in class differed significantly. In the writing section of the questionnaire, writing poems was the only task towards which the boys in the CLIL classes had significantly more negative attitudes than the girls in the same classes. However, in the other classes boys gave, in addition, significantly more negative answers to the questions about being an author in the future, about writing to a pen friend, about keeping a diary, and about editing their texts.

When one examines the answers given to the questions on learning English, the difference between the students' attitudes in the CLIL classes and the other classes is clear. The students in the CLIL classes had significantly more positive opinions towards studying English than their peers in the regular classes ( $t=4.86, p=.000)$. The total scores of the language learning section were significantly higher in the CLIL classes than in the other classes. It is worth mentioning that there was a significant difference $(t=-2.98, p=.004)$ in the total scores of the boys and the girls in the other classes whereas this was not the case in the CLIL classes.

The results show that especially the boys seemed to benefit from the CLIL education. They had more positive attitudes towards reading and writing than the boys in the other classes. Consequently, they read more than the boys in other classes and as the results of the sixth grade reading and writing tests show, this had had a positive effect on their literacy skills.

\section{Conclusion}

The results of the study showed that bilingual education had not affected the development of the students' first language literacy skills negatively. After six study years the students in the CLIL classes had achieved significantly better spelling skills than the students in the other classes. Furthermore, the dissimilarities in spelling English and Finnish language did not seem to cause errors in writing Finnish. For instance, the different ways of writing compound words and using capital letters in the two languages had not increased the number of these errors in the CLIL classes. On the contrary, the students in the CLIL classes made them significantly less than the students in the other classes.

In sixth grade, the students in the CLIL classes understood different texts better than their peers in the other classes. They succeeded equally well in comprehending fiction, non-fiction and newspaper texts while the students in the other classes had much more difficulties in understanding the non-fiction text and the newspaper article than the narrative text. The 
students in the CLIL classes showed more proficiency in deriving the meaning of new words from the written context than the other students. This may be because they had learned to do that when reading and hearing the English language which often includes words unknown to them. In addition, they succeeded significantly better in finding the most important facts of the non-fiction text and summarising the text than their peers in the other classes.

The results revealed that in the CLIL classes the students' attitudes towards reading and writing were more positive than the attitudes of their peers in the regular classes. Although the boys, at the age of ten, did not appear to be as interested in reading and writing as the girls, the difference between the attitudes of the two genders was not as apparent in the CLIL classes as in the other classes. Moreover, in the regular classes there was a significant difference between the boys' and the girls' attitudes towards language learning, whereas this was not the case in the CLIL classes.

Still, when assessing the results of the study it is necessary to keep in mind certain facts: Firstly, most parents whose children studied in the CLIL classes were interested in their children's studies and sought to help them to succeed in them. They attended parent-teacher meetings more often than parents on average. Furthermore, it is possible that they encouraged their children to read and write also outside school more often than other parents. All this has had a positive effect on the children's development. Secondly, the students in the CLIL classes showed, as a group, a higher starting level in the initial test six years earlier. Nevertheless, also in the CLIL classes there were children who at the beginning of the first grade showed poor starting level and in the regular classes children who showed excellent performance in the initial test. However, the results of the study show that even when the different starting levels of the two groups were taken in account the students' reading and writing skills developed at least equally well in CLIL education as when the students studied exclusively in their mother tongue. Studying through one or two languages did not appear to have any significant effect on the development of a student's literacy skills when his or her starting level at the beginning of the first school year had been poor of excellent.

The students in the CLIL classes had learned to pay attention to languages, as well to their mother tongue as to other languages. They were aware of several similarities and dissimilarities in the languages. For instance, in fourth grade the most distinguishable differences between the stories composed in the CLIL classes and in the other classes were related to the writers' consciousness of the existence of different languages. It was obvious that languages played a more important role in the lives of the students studying in the CLIL classes than for the students in the other classes.

\section{References}

Beardsmore, H. (2009). Language promotion by European supra-national institutions. In O. García (Ed.), Bilingual education in the 21st century (pp. 197-217). Chichester: Wiley-Blackwell.

Berninger, V.W., Abbott, R.D., Whitaker, D., Sylvester, L., \& Nolen, S.B. (1995). Integrating low- and high-level skills in instructional protocols for writing disabilities. Learning Disability Quarterly, 18(4), 293-309.

Bowyer-Grane, C. \& Snowling, M.J. (2005). Assessing children's inference generation: What do tests of reading comprehension measure? British Journal of Educational Psychology, 75(2), 189-201.

Coiro, J., \& Dobler, E. (2007). Exploring the online reading comprehension strategies used by sixth-grade skilled readers to search for and locate information on the Internet. Reading Research, Quarterly, 42(2), 214-257.

Commission of the European Communities (2012). Language competences for employability, mobility and growth. Commission staff working document. Strasbourg: Commission of the European Communities. Retrieved June 08.2014, from http://eur-lex.europa.eu/legal-content/EN/TXT/PDF/?uri=CELEX:52012SC0372\&from=EN

Commission of the European Communities (2007). Framework for the European survey on language competences. Brussels: Commission of the European Communities. Retrieved June 08.2014, from http://eur-lex.europa.eu/ LexUriServ/LexUriServ.do?uri=COM\%3A2007\%3A0184\%3AFIN\%3AEN\%3AHTML

Content and language integrated learning at school in Europe (2005). Brussels: Eurydice.

Dalton-Puffer, C. (2011). Content-and-Language Integrated Learning: From Practice to Principles? Annual Review of Applied Linguistics, 31, 182-204.

Diehl, H.L. (2005). Snapshots of our journey to thoughtful literacy. The Reading Teacher, 59(1), 56-69.

García, O. (2009). Bilingual Education in the 21st Century. Chichester: Wiley-Blackwell. 
Hannon, P. (1997). Literacy, Home and School: Research and Practice in Teaching Literacy with Parents. London: The Falmer Press.

Hedge, T. (2000). Teaching and Learning in the Language Classroom. Oxford: Oxford University.

Hurry, J. \& Doctor, E. (2007). Assessing Literacy in Children and Adolescents. Child and Adolescent Mental Health, 12(1), $38-45$.

Krashen, S.D. (1992). Comprehensive Input and Some Competenting Hypotheses. In R.J. Courchêne, J.I. Glidden, J. St.John \& C. Thérien (Eds.), Comprehension-Based Second Language Teaching (pp. 19-37). Ottawa: Ottawa University.

McGee, A. \& Johnson, H. (2003). The effect of inference training on skilled and less skilled comprehenders. Educational Psychology, 23(1), 49-59.

Merisuo-Storm, T. (2006). Girls and boys like to read and write different texts. Scandinavian Journal of Educational Research, 50(2), 111-125.

Met, M. (2004). Improving students' capacity in foreign languages. Phi Delta Kappan, 86(3), 214-218.

National Core Curriculum for Basic Education (2004). Helsinki: Finnish National Board of Education.

Nikula, T., Dalton-Puffer, C., \& Llinares, A. (2013). CLIL classroom discourse. Research from Europe. Journal of Immersion and Content-Based Language Education 1(1), 70-100.

Nolen, S.B. (2007). Young children's motivation to read and write: Development in social contexts. Cognition and Instruction, 25(2), 219-270.

OECD. (2013). PISA 2012 Results in Focus. What 15-year-olds know and what they can do with what they know. Paris: OECD.

Richards, J.C., \& Rodgers, T.S. (2001). Approaches and methods in language teaching (2nd ed.). Cambridge: Cambridge University.

Scharer, P.L., Pinnell, G.S., Lyons, C., \& Fountas, I. (2005). Becoming an engaged reader. Educational Leadership, 63(2), 24-26.

Välïärvi, J., Kupari, P., Linnakylä, P., Reinikainen, P., Sulkunen, S., Törnroos, J., \& Arffman, I. (2007). The Finnish success in PISA - and some reasons behind it 2. University of Jyväskylä.

Whitehead, M. (1999). Supporting Language and Literacy Development in the Early Years. Buckingham: Open University Press. 
Tables

Table 1. Differences between Bilingual and Language Education

\begin{tabular}{l|l|l}
\hline & Bilingual Education & $\begin{array}{c}\text { Foreign or Second-Language } \\
\text { Education }\end{array}$ \\
\hline OVERARCHING GOAL & $\begin{array}{l}\text { Educate meaningfully and } \\
\text { some type of bilingualism }\end{array}$ & $\begin{array}{c}\text { Competence in additional } \\
\text { language }\end{array}$ \\
\hline ACADEMIC GOAL & $\begin{array}{l}\text { Educate bilingually and } \\
\text { be able to function across } \\
\text { cultures }\end{array}$ & $\begin{array}{l}\text { Learn an additional language } \\
\text { and become familiar } \\
\text { with an additional culture }\end{array}$ \\
\hline LANGUAGE USE & $\begin{array}{l}\text { Languages used as media of } \\
\text { instruction }\end{array}$ & $\begin{array}{l}\text { Additional language taught } \\
\text { as subject }\end{array}$ \\
\hline $\begin{array}{l}\text { INSTRUCTIONAL USE } \\
\text { OF LANGUAGE }\end{array}$ & $\begin{array}{l}\text { Uses some form of two } \\
\text { or more languages }\end{array}$ & $\begin{array}{l}\text { Uses target language mostly } \\
\text { PEDAGOGICAL }\end{array}$ \\
$\begin{array}{l}\text { Intergration of language and } \\
\text { EMPHASIS }\end{array}$ & Explicit language instruction \\
\hline
\end{tabular}

Source: From García, 2009

Table 2. The five measurements conducted during the research period

\begin{tabular}{|c|c|c|}
\hline \multicolumn{3}{|c|}{ MEASUREMENTS } \\
\hline Measurement 1 & Measurement 2 & Measurement 3 \\
\hline $\begin{array}{l}\text { FIRST GRADE AUTUMN } \\
\text { - school readiness } \\
\text { - auditory perception } \\
\text { - visual perception } \\
\text { - mathematical skills } \\
\text { - memory }\end{array}$ & $\begin{array}{l}\text { FIRST GRADE SPRING } \\
\text { - reading accuracy } \\
\text { - reading speed } \\
\text { - reading comprehension } \\
\text { - spelling }\end{array}$ & $\begin{array}{l}\text { SECOND GRADE SPRING } \\
\text { - reading accuracy } \\
\text { - reading speed } \\
\text { - reading comprehension } \\
\text { - spelling }\end{array}$ \\
\hline Measurement 4 & \multicolumn{2}{|l|}{ Measurement 5} \\
\hline $\begin{array}{l}\text { FOURTH GRADE SPRING } \\
\text { - attitudes towards reading } \\
\text { - attitudes towards writing } \\
\text { - attitudes towards language } \\
\text { learning } \\
\text { - creative writing }\end{array}$ & \multicolumn{2}{|c|}{$\begin{array}{l}\text { SIXTH GRADE SPRING } \\
\text { - reading comprehension (fiction, newspaper text) } \\
\text { - deriving word meaning from context (fiction, newspaper text) } \\
\text { - summarizing (non-fiction) } \\
\text { - spelling }\end{array}$} \\
\hline
\end{tabular}

Table 3. The percentage distribution of the students' marks of the writing from dictation test in the CLIL classes and the other classes

\begin{tabular}{l|c|c}
\multicolumn{3}{c}{ SPELLING IN SIXTH GRADE } \\
\hline marks & $\begin{array}{c}\text { CLIL classes } \\
\mathrm{n}=62\end{array}$ & $\begin{array}{c}\text { other classes } \\
\mathrm{n}=71\end{array}$ \\
\hline excellent & $23 \%$ & $10 \%$ \\
good & $70 \%$ & $56 \%$ \\
fair & $7 \%$ & $24 \%$ \\
poot & - & $10 \%$
\end{tabular}


Table 4. The percentage distribution of the students' marks in the fiction section of the reading comprehension test in the CLIL classes and the other classes

\begin{tabular}{|c|c|c|}
\hline \multicolumn{3}{|c|}{$\begin{array}{l}\text { READING COMPREHENSION } \\
\text { IN SIXTH GRADE } \\
\text { (fiction) }\end{array}$} \\
\hline marks & $\begin{array}{c}\text { CLIL classes } \\
n=62\end{array}$ & $\begin{array}{c}\text { other classes } \\
\mathrm{n}=71\end{array}$ \\
\hline excellent & $8 \%$ & $3 \%$ \\
\hline yery good & $32 \%$ & $20 \%$ \\
\hline good & $48 \%$ & $57 \%$ \\
\hline $\begin{array}{l}\text { fair } \\
\text { faod }\end{array}$ & $11 \%$ & $16 \%$ \\
\hline poor & $l \%$ & $54 \%$ \\
\hline
\end{tabular}

Table 5. The percentage distribution of the students' marks in the newspaper section of the reading comprehension test in the CLIL classes and the other classes

\begin{tabular}{c|c|c}
\multicolumn{3}{c}{$\begin{array}{c}\text { READING COMPREHENSION } \\
\text { IN SIXTH GRADE } \\
\text { (newspaper) }\end{array}$} \\
\hline \multicolumn{1}{c|}{ marks } & $\begin{array}{c}\text { CLIL classes } \\
\mathrm{n}=62\end{array}$ & $\begin{array}{c}\text { other classes } \\
\mathrm{n}=71\end{array}$ \\
\hline exeellent & $9 \%$ & $3 \%$ \\
very good & $34 \%$ & $22 \%$ \\
good & $48 \%$ & $50 \%$ \\
fair & $9 \%$ & $20 \%$ \\
poor & - & $5 \%$
\end{tabular}

Table 6. The percentage distribution of the students' marks in the summarizing section of the reading comprehension test in the CLIL classes and the other classes

\begin{tabular}{l|c|c}
\multicolumn{2}{c}{$\begin{array}{r}\text { READING COMPREHENSION } \\
\text { IN SIXTH GRADE } \\
\text { (summarizing) }\end{array}$} \\
\hline marks & $\begin{array}{c}\text { CLIL classes } \\
\mathrm{n}=62\end{array}$ & $\begin{array}{c}\text { other classes } \\
\mathrm{n}=71\end{array}$ \\
\hline exoellent & $13 \%$ & $2 \%$ \\
very good & $34 \%$ & $9 \%$ \\
good & $40 \%$ & $43 \%$ \\
fair & $11 \%$ & $37 \%$ \\
poor & $2 \%$ & $9 \%$
\end{tabular}

